\title{
How different are ICT-supported pedagogical practices from extensive and non-extensive ICT-using science teachers?
}

\author{
Joke Voogt
}

Published online: 21 May 2009

(C) The Author(s) 2009. This article is published with open access at Springerlink.com

\begin{abstract}
This paper aims to understand the differences between characteristics of ICT-supported pedagogical practices of grade 8 science teachers of extensive and non-extensive ICT-using science teachers. The differences of the pedagogical practices are described in terms of innovative and traditionally important practice orientations. The innovative practice orientation reflects a demand for education in an information society (e.g. communication skills; ability to learn at own pace), while the traditionally important practice orientation (e.g. subject-matter knowledge) reflects teaching and learning in an industrial society. The purpose of this study was to explore differences between the ICT-supported pedagogical practices of extensive and non-extensive ICT-using science teachers. As part of the SITES 2006 study extensive ICT-using science teachers nominated their most satisfying pedagogical practice. Perceived student outcomes and teaching practices have been analyzed using the SITES 2006 database. In addition, the regular pedagogical practices of these science teachers were, using the SITES 2006 database, compared with the regular pedagogical practices of non-extensive ICT-using science teachers. The results show that although traditionally important practices within the context of ICT are still dominant in science education, changes in the equilibrium between traditionally important and innovative practice orientations are taking place across educational systems.
\end{abstract}

Keywords International comparative research - Secondary education .

Science education $\cdot$ Teaching practice $\cdot$ Student outcomes $\cdot$ Science teacher

\section{Introduction}

Through Information and Communication Technology our society is changing from an industrial society to an information or knowledge society. While in the industrial

J. Voogt $(\bowtie)$

University of Twente, P.O. Box 217, 7500AE Enschede, The Netherlands

e-mail: j.m.voogt@utwente.nl 
society the main focus of education is to contribute to the development of factual and procedural knowledge, in the information or knowledge society the development of conceptual and meta-cognitive knowledge is increasingly considered important (Anderson 2008). This change should have implications for our education systems. There is a need to drastically change curricula so that students develop competencies which are often not addressed in the industrial society's curricula, but are needed in the 21st century (e.g. Anderson 2008; Voogt and Pelgrum 2005). According to the European Commission, for instance, all citizens of the European Union should have the opportunity to acquire a number of so called key skills, which include digital literacy and higher-order skills such as teamwork, problem solving, and project management (European Commission 2002). Key skills are often also referred to as lifelong learning competencies. The education ministers of OECD countries (OECD 2004) embraced the concept of lifelong learning, which covers all purposeful learning activities in a person's life. A major feature of lifelong learning is developing meta-cognitive knowledge and skills.

Developments in the learning sciences (see, for example, Bransford et al. 2000) show the benefits of learner-centered forms of instruction. Students are expected to be more actively involved in their own learning process, which asks for different teaching strategies and a change in the responsibilities that students and teachers traditionally have held within the learning process. These findings from research are consistent with the importance policymakers attach to "lifelong learning" and "learning-to-learn" competencies. Voogt (2003), based on a review of the literature, projected pedagogical approaches consistent with the expectations and values of the information society and showed how these might differ from those consistent with the expectations and values of the industrial society (see Table 1). According to Voogt the pedagogical approaches which are expected to be important in the

Table 1 Overview of pedagogy in an industrial society versus an information society (source Voogt 2003)

\begin{tabular}{lll}
\hline Aspect & Less (pedagogy in an industrial society) & More (pedagogy in the information society) \\
\hline Active & Activities prescribed by teacher & Activities determined by learners \\
& Whole class instruction & Small groups \\
& Little variation in activities & Many different activities \\
& Pace determined by the program & Pace determined by learners \\
Collaborative & Individual & Working in teams \\
& Homogeneous groups & Heterogeneous groups \\
Creative & Everyone for him/herself & Supporting each other \\
& Reproductive learning & Productive learning \\
Integrative & Apply known solutions to problems & Find new solutions to problems \\
& No link between theory and practice & Integrating theory and practice \\
& Separate subjects & Relations between subjects \\
& Discipline-based & Thematic \\
Evaluative & Individual teachers & Teams of teachers \\
& Summative & Student-directed \\
& Suched & Diagnostic \\
& &
\end{tabular}


information society have, amongst others, more to do with providing variety in learning activities, offering opportunities for students to learn at their own pace, encouraging collaborative work, focusing on problem-solving, and encouraging student involvement in assessment. Voogt (2003) argues that education needs to find a new balance between the pedagogical approaches that are considered useful in the industrial society and those that are deemed relevant for the information society. For the present study, however we make a distinction between the two pedagogical approaches.

IEA conducted from 1998 till 2006 the Second Information Technology in Education Study (SITES). This study consisted of three modular studies with the purpose to study to what extent and how education is responding to the requirements of the information society, and how ICT is impacting on these changes. Several terms have been used in the three SITES studies to distinguish between educational practices that are associated with the information society and the industrial society respectively. An overview of the terminology used in the different SITES studies is presented in Table 2.

In the first SITES study (Module 1 with data collection in 1998) a distinction was made between the traditionally important and the emerging paradigm for learning (Pelgrum and Anderson 1999). The latter reflected the challenges for education in the information society. In this study school principals were asked to describe the most satisfying example of ICT-use in their school. Voogt (1999) showed that many principals were already able to provide examples of satisfying experiences with pedagogical use of ICT in 1998. It was remarkable that, across education systems, a fairly large number of these satisfying experiences contained pedagogical practices such as those reflected in the 3rd column of Table 1, and hence were consistent with the notion of the emerging paradigm. The second SITES study (Module 2, with data collection in 2002) used the term 'innovative pedagogical practices'. In this study indepth case studies (174 cases from 28 countries) were conducted to study the characteristics of innovative examples of ICT-using pedagogical practice. The analysis of the SITES Module 2 showed amongst others that in the innovative practices involved in the study students had developed not only subject-matter

Table 2 Overview of terminology used in the different SITES studies to associate educational practices with the industrial society and the information society

\begin{tabular}{llll}
\hline Study & Study characteristics & $\begin{array}{l}\text { Terminology used } \\
\text { for education associated } \\
\text { with the industrial society }\end{array}$ & $\begin{array}{l}\text { Terminology used } \\
\text { for education associated with } \\
\text { the information society }\end{array}$ \\
\hline $\begin{array}{c}\text { SITES } \\
\text { Module } \\
1\end{array}$ & $\begin{array}{c}\text { Survey for principals and } \\
\text { technical coordinators }\end{array}$ & $\begin{array}{c}\text { Traditionally important } \\
\text { paradigm }\end{array}$ & Emergent paradigm \\
$\begin{array}{c}\text { SITES } \\
\text { Module }\end{array}$ & Case studies & - & $\begin{array}{c}\text { Innovative pedagogical } \\
\text { practices using technology }\end{array}$ \\
$\begin{array}{c}\text { SITES } \\
2006\end{array}$ & $\begin{array}{c}\text { Survey for principals, technical } \\
\text { coordinators and maths and } \\
\text { science teachers }\end{array}$ & $\begin{array}{l}\text { Traditionally important } \\
\text { practice } \\
\text { orientation }\end{array}$ & $\begin{array}{l}\text { Innovative practice } \\
\text { orientation: } \\
\text { lifelong learning } \\
\text { orientation }+\end{array}$ \\
& & & connectedness orientation \\
\hline
\end{tabular}


knowledge, but also information-handling, collaboration, and communication skills (Kozma 2003), skills which are considered important for the information society. The Module 2 findings were based on a selection of specific schools where innovative pedagogy — as locally defined-was used. Hence Module 2 did not provide a representative picture of (innovative) ICT-supported pedagogical practices in the education system at large. This situation was the main reason to explore in SITES 2006 (with data collection in 2006) to what extent satisfying ICT-supported pedagogical practices as provided by extensive ICT-using math and science teachers, could be associated with the traditionally important practice orientation or the innovative practice orientation. Within the innovative practice orientation, SITES 2006 made a distinction between the lifelong learning orientation and the connectedness orientation (Law et al. 2008). The lifelong learning orientation 'includes the use of more collaborative-, inquiry-, and production-oriented activities as well as strategies designed to take greater account of individual differences' (Law and Chow 2008, p.122). The connectedness orientation refers to 'activities in which students collaborate with/ and or learn from outside peers and experts to create products and publish results' (Law and Chow 2008, p. 122). In this paper we prefer to use the term innovative practice orientation for the combination of the lifelong learning orientation and the connectedness orientation.

In this study we explored the characteristics of satisfying ICT-supported pedagogical practices, which were nominated by grade 8 science teachers, with respect to perceived student outcomes, teaching practices, and responsibility for various aspects of teaching and learning (see also Voogt 2008). The first research question that we aim to answer is 'How do science teachers characterize satisfying ICT-supported pedagogical practices with respect to student outcomes, teaching practices, and distribution of responsibility for aspects of teaching and learning? The results are analyzed in terms of innovative and traditionally important practice orientations. In addition, we conducted a secondary analysis. We compared the regular pedagogical practices of extensive ICT-using science teachers (the teachers who provided the satisfying ICT-supported practices) with the regular pedagogical practices of science teachers who are not extensively using ICT. The second research question that we aim to answer is 'How do regular pedagogical practices differ between teachers who use ICT extensively with teachers who do not use ICT extensively?' To answer these questions teacher data from the SITES 2006 was used.

\section{Design of the study}

To determine whether science teachers who were sampled to participate in the SITES 2006 survey $^{1}$ used ICT extensively two questions were asked. In the first question teachers were asked whether they 'used ICT in teaching and learning activities in grade 8 '. In the second question science teachers were asked to indicate whether they used ICT 1) 'once a week or more in grade 8', 2) 'extensively in grade 8 during a limited period in the year (e.g., in a project)', or 3) 'none of the above'. Only those

\footnotetext{
${ }^{1}$ Data were collected from science teachers of 21 education systems who participated in the SITES 2006 study.
} 
science teachers who answered in the affirmative to the first question were selected for the analysis conducted for this study. Science teachers were considered to use ICT extensively when they had answered the second question with option 1 ('once a week or more') or 2 ('extensively during a limited period in the school year'). Teachers' use of ICT in their teaching or learning was considered less extensive when they answered the second question with option 3 ('none of the above'). A weighting procedure was used to correct the different sample sizes of teachers in the countries participating in the study (Carstens and Pelgrum 2009).

The data from 8834 science teachers (after weighting) answered the two questions above and could be used for the analysis of this study. Of these science teachers $47.0 \%(N=4152)$ either used ICT once a week or more $(19.9 \%, N=1754)$ in grade 8 , or used ICT extensively during a limited period in the school year $(27.1 \%, N=2398)$. $14.4 \%(N=1273)$ of the science teachers did use ICT, but did not make extensive use of ICT in their teaching practice. Of the remaining science teachers $30.3 \%(N=2679)$ did not use ICT. A few teachers $(8.3 \%, N=730)$ provided an invalid answer to these questions and had to be excluded in the further analysis.

Figure 1 presents the results per country of the percentage of science teachers who were using ICT and the extent to which they used ICT (once a week, during a limited period in the school year, not so extensive, not at all). It should be noted that in 13 education systems more than one third of the teachers do not use ICT at all. In most educational systems, ICT-using science teachers use ICT during limited periods in the school year (during a theme or a project). In Alberta, Canada, Chile, Hong Kong, Italy and Ontario, Canada, the ICT-using teachers are using ICT mostly on a weekly basis. In Catalonia, Spain, Finland, France, Japan, Chinese Taipei, and South Africa a fairly large number of ICT-using science teachers do not use ICT extensively.

To answer the first research question the teachers $(20.2 \%, N=1696)$ who were considered extensive users of ICT (once a week or during a limited period in the school year) were asked to provide a description (in 20 words) of a satisfying pedagogical practice, in which they and/or their grade 8 students used ICT extensively for teaching and learning of specific content related to science. A few examples of the brief descriptions that teachers provided are given in Fig. 2.

With this specific pedagogical practice in mind the teachers were asked to complete three closed-item questions on the following:

- the contribution of ICT on changes in student outcomes (11 outcomes were distinguished, amongst them subject-matter knowledge; learning motivation; information-handling skills);

- changes in their teaching practice (14 teaching aspects were distinguished, amongst them quality of coaching; time needed for technical problems; availability of new learning content);

- the main initiating actor (teacher/student) in aspects of teaching and learning (13 teaching/learning aspects were distinguished, such as determining content; organizing grouping; choosing learning activities).

The first two questions had a three-point scale (increase - no difference - decrease). For the third question teachers could choose between 'teacher' or 'student' as main initiating actor, or not applicable (NA). 


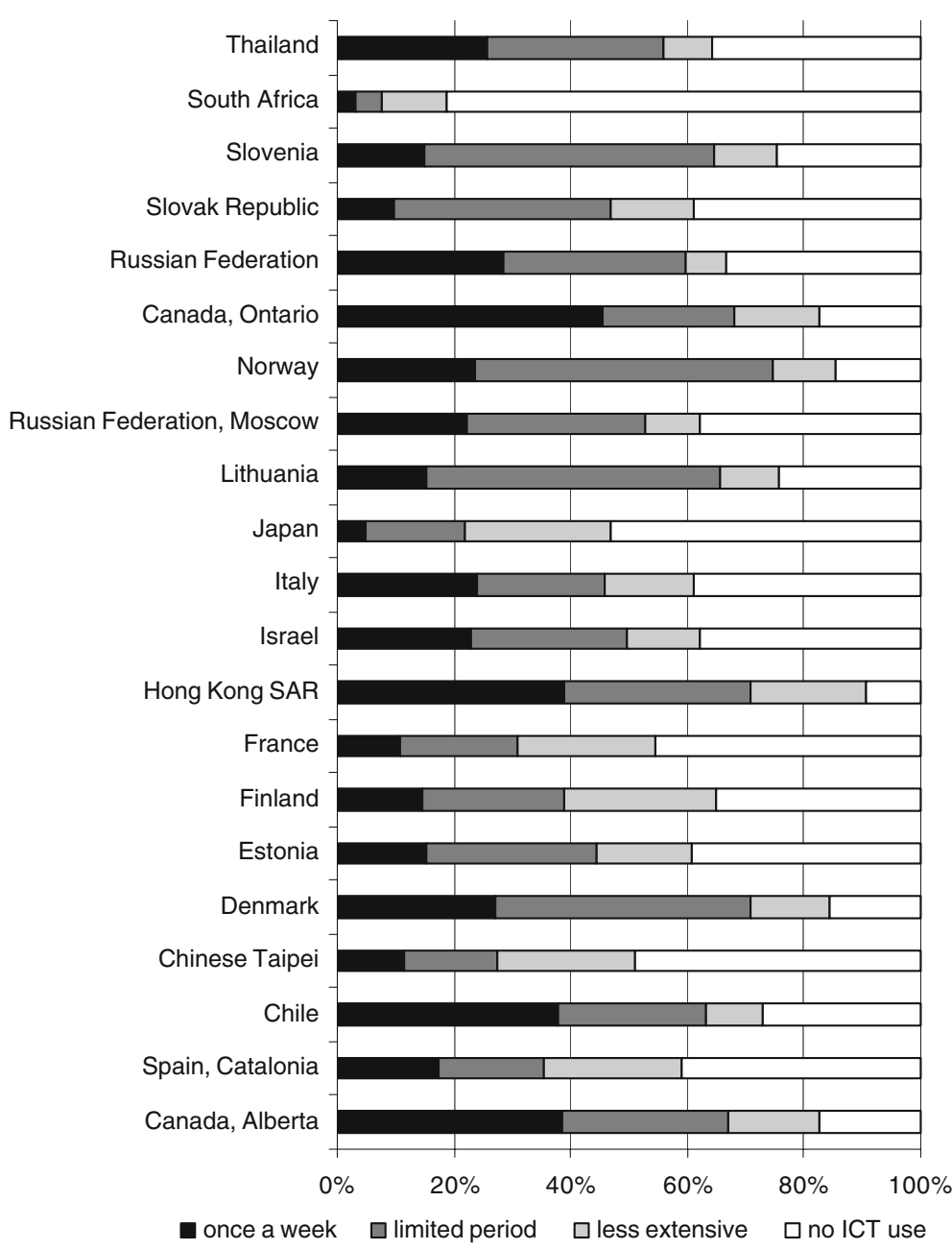

Fig. 1 Extent of ICT use by grade 8 science teachers

Voogt (2008) showed that teachers who use ICT on a weekly basis reported more changes due to ICT in their pedagogical practices as compared to teachers who use ICT somewhat extensively only during limited periods in the school year. Therefore in this paper we use only those teachers who use ICT on a weekly basis in the analysis conducted for answering the second research question. In the analysis for this question we compare the pedagogical practices of those teachers who use ICT once a week or more $(N=1696)$ with the pedagogical practices of those teachers who are said to use ICT, but not in such an extensive manner $(N=1229)$. We compare the two groups of teachers based on a number of indicators taken from the main teacher survey, viz. the use of learning resources, teaching practices, student practices, and the perceived impact of ICT on student outcomes. Besides means and standard deviations, effect sizes (Cohen's d) are also calculated. Cohen (1969) provided tentative benchmarks for the interpretation of effect sizes. He considers $d=0.2$ a 


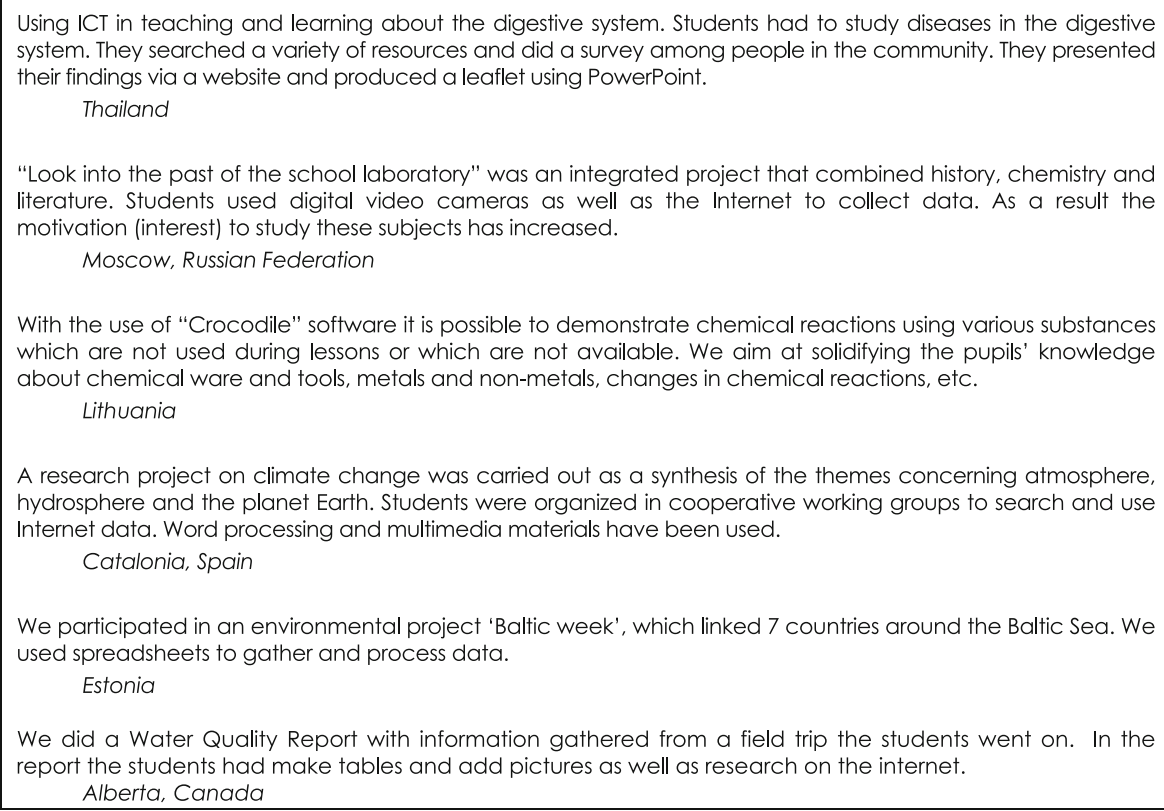

Fig. 2 Examples of ICT-supported satisfying practices provided by grade 8 science teachers

small, $d=0.5$ a medium and $d=0.8$ a large effect size. In this paper we take a somewhat more conservative position and consider an effect size between $\geq 0.5$ but $<0.8$ as a medium size effect and an effect size $\geq 0.8$ as a large size effect.

\section{Results}

\subsection{Characteristics of satisfying ICT-supported pedagogical practices}

The results related to the first research question are presented in this section. In this section the characteristics of satisfying ICT-supported practices are presented as reported by science teachers. First the perceived changes in student outcomes are presented; this is followed by a description of the perceived changes in teaching practices, and a characterization of how science teachers perceive the distribution of responsibilities between teachers and students on aspects of teaching and learning.

\subsubsection{Changes in student outcomes}

The extensive ICT-using science teachers were asked whether the use of ICT in the pedagogical practice they had in mind contributed to changes in students' outcomes. Figure 3 presents the results. It is worth mentioning that the majority of the teachers perceived an increase or no change in student outcomes due to the use of ICT in the pedagogical practice. Figure 2 shows that the majority of the science teachers of 


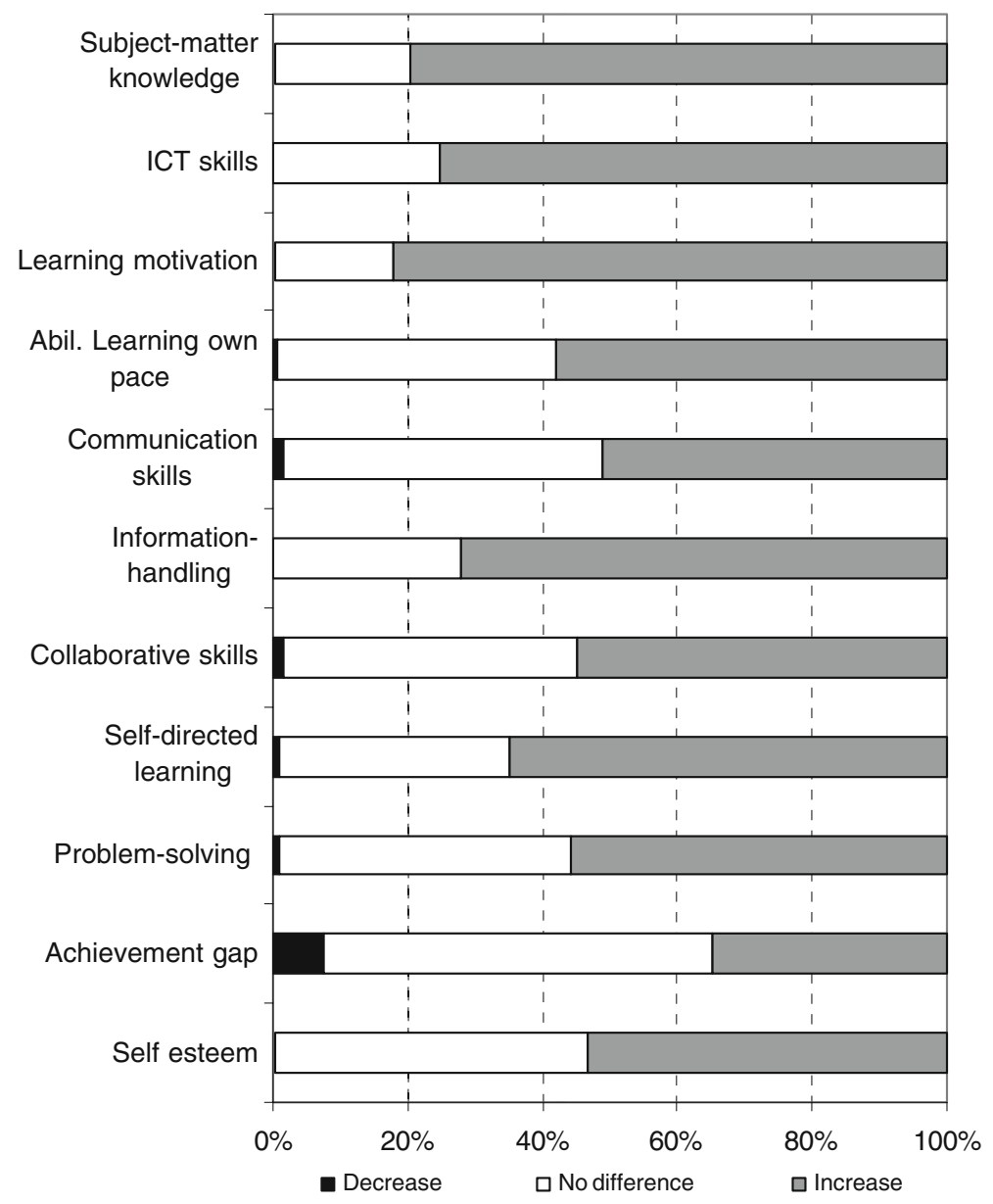

Fig. 3 Science teachers' perceptions of changes in student outcomes due to ICT

grade 8 reported an increase in student outcomes on all but one item (achievement gap) for their specified pedagogical practice. More than $70 \%$ of the science teachers report that student outcomes increased with respect to learning motivation, ICTskills, information-handling skills, and subject-matter knowledge. These results show that next to learning outcomes relevant for the traditionally important practice orientation (such as subject matter knowledge and ICT skills) student outcomes, that are considered relevant for the innovative practice orientation (such as ability to work at own pace, information-handling, communication, collaborative, problemsolving and self-directed learning skills), also increased as a result of ICT use in the pedagogical practices teachers had nominated as most satisfying. According to many teachers, students' learning motivation and self esteem also increased due to ICT, which is beneficial for both the innovative and traditionally important practice orientations. It should be noted, however, that according to about $35 \%$ of the science teachers, differences in achievement between students increased, and decreased according to only $7 \%$ of the teachers. 


\subsubsection{Changes in teaching practice}

Extensive ICT-using science teachers were also asked whether the use of ICT in the pedagogical practice they had specified had contributed to changes in their teaching practices in grade 8 . The results are presented in Fig. 4. The greater part of the science teachers reported that ICT in the pedagogical practice had led to an increase in the variety of the learning activities (85\%); the quality of coaching $(54 \%)$; the quality of classroom discussion (55\%); and the collaboration between students $(55 \%)$. They also reported that they were better able to adapt to the individual needs of their students (59\%). Such teaching practices are considered relevant in the innovative practice orientation.

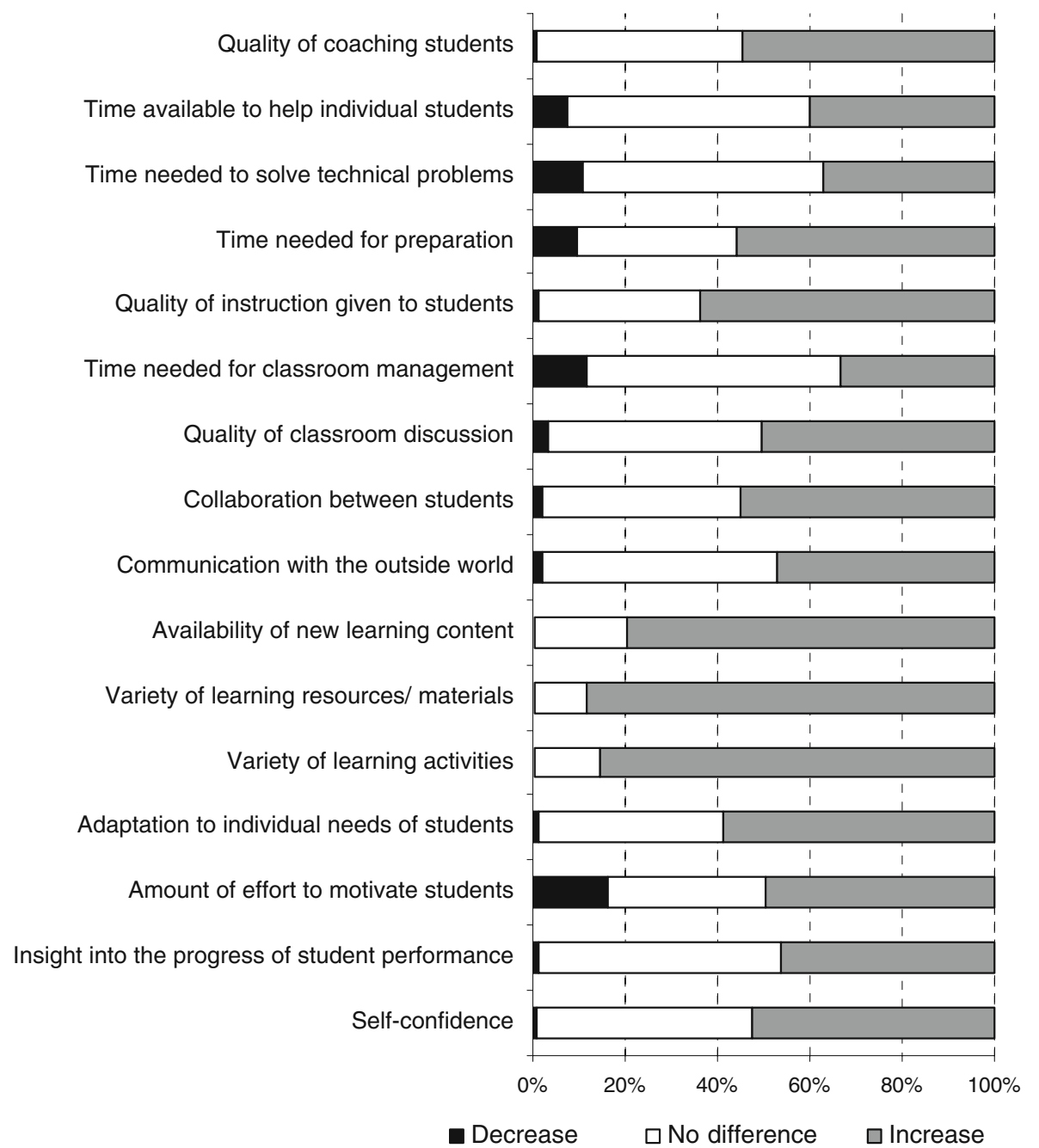

Fig. 4 Science teachers' perceptions of changes in teaching practices due to ICT use in the specified pedagogical activity 
On the other hand the science teachers also reported an increase in quality of instruction (64\%), which is seen as part of the traditionally important practice orientation. A large majority of the science teachers also observed that ICT had contributed to an increase in available content (82\%) and in an increase in the variety of available learning resources (88\%). These benefits of ICT are relevant for the innovative as well as traditionally important practice orientation.

Time needed for classroom management (33\%), for solving technical problems (37\%), and for coaching individual students $(40 \%)$ had increased for only a minority of the science teachers. About half of the science teachers mentioned an increase in the amount of effort needed to motivate students. In addition more than half of the science teachers reported that the time they needed for preparation had increased (56\%). The two latter results may indicate that many teachers were making considerable effort to prepare teaching-learning practices that would motivate their students.

A little less than half of the science teachers observed that ICT had increased their insight into students' progress (46\%) and in communication with the outside world (47\%). Finally many science teachers reported that ICT had led to an increase in self-confidence $(53 \%)$.

\subsubsection{Distribution of responsibility between teachers and learners}

In the information society students have to learn to take more responsibility for their learning process. For this reason we asked the extensive ICT-using science teachers to identify who was the main initiator of a number of aspects of teaching and learning in the pedagogical practice that they had nominated as satisfying. The results, presented in Fig. 5, clearly show that, for all aspects of teaching and learning, most of the grade 8 science teachers reported themselves as the main initiators of teaching and learning in the pedagogical practice they had specified. However, a relatively large number of science teachers - somewhat under half said that their grade 8 students initiated the organization of group work (45\%) and took the initiative to demonstrate their achievement (42\%). About one quarter of the extensive ICT-using science teachers reported that the use of ICT had led to an increase in students choosing their learning resources (27\%), and making decisions about the time they needed to study a topic (24\%). For all other aspects of teaching and learning, less than $20 \%$ of the science teachers reported that their students took the initiative.

\subsection{Pedagogical practices of extensive and non-extensive ICT-using science teachers}

In this section the results related to the second research question - 'How do regular pedagogical practices differ between teachers who use ICT extensively with teachers who do not use ICT extensively?' - are presented. The regular pedagogical practices as reported by science teachers who use ICT on a weekly basis (further addressed as extensive ICT-using science teachers) are compared with the pedagogical practices as reported by science teachers who do not use ICT extensively (further addressed as non-extensive ICT-using science teachers). The regular pedagogical practices of these two groups of teachers are compared with respect to learning resources, teaching practices, student practices, and student outcomes. 


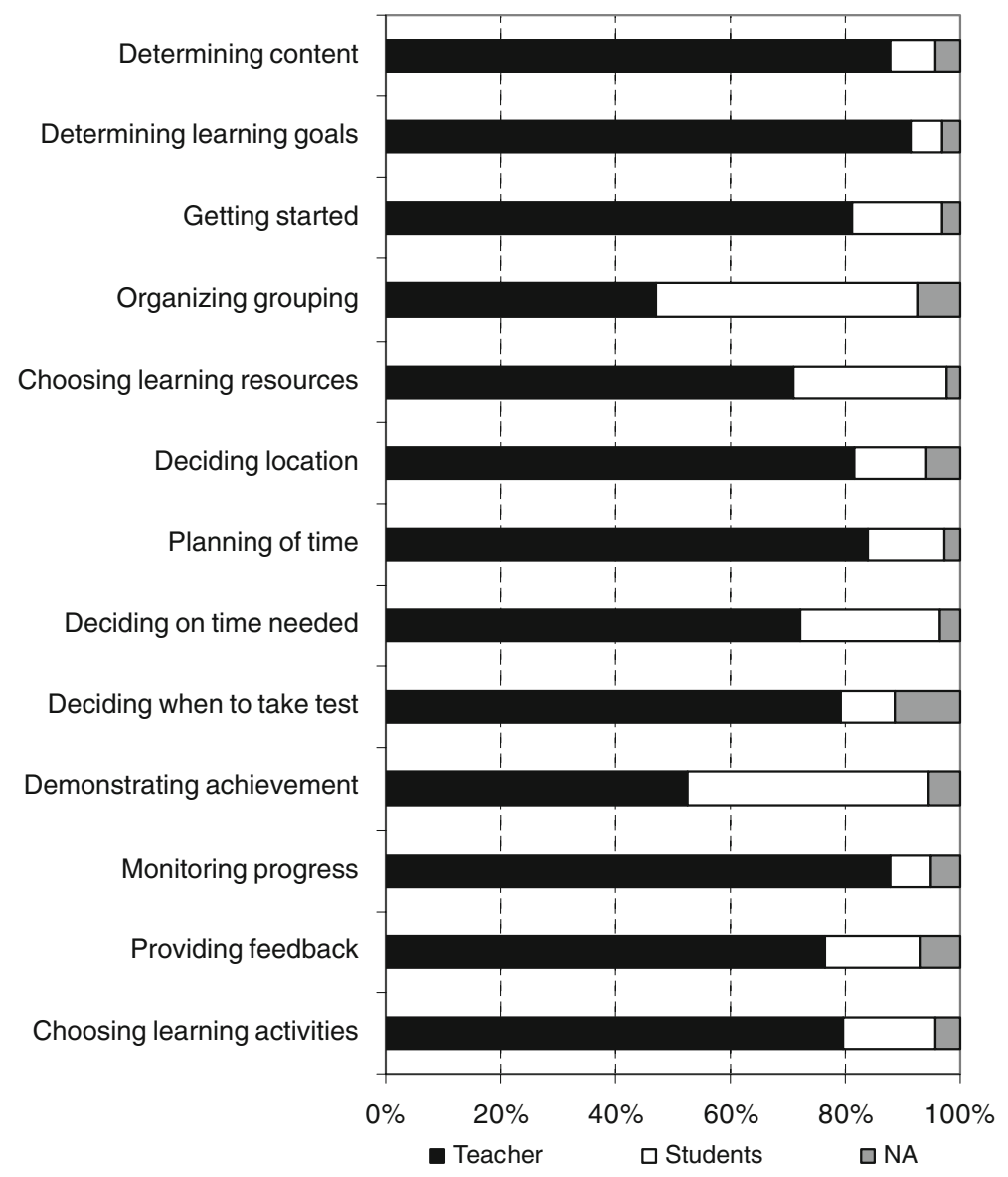

Fig. 5 Science teachers' identification of person initiating aspects of teaching and learning (teacher, students or not applicable-NA)

\subsubsection{Learning resources}

In Table 3 the difference between science teachers who use ICT extensively and those who do not use ICT extensively with regard to the frequency in which they make use of learning resources in their teaching is presented. The results show that science teachers who use ICT extensively (that is once a week or more) use each of the learning resources more often than science teachers who do not use ICT in such an extensive manner. By comparing the rank order in which extensive and nonextensive science teachers use the various learning resources, information about the relative use of the activities is obtained. The rank order of use of learning resources shows only small differences between extensive and non-extensive users. Both groups first of all make use of 'traditional' equipment and hands-on materials (such as laboratory equipment, overhead projectors, and electronic calculators), which is followed by general office software, digital information resources from the WWW, and tutorials. While no meaningful effect sizes were found for the use of traditional 
Table 3 Comparison of use of learning resources of extensive and non extensive ICT-using science teachers (M, SD, and effect size)

\begin{tabular}{|c|c|c|c|c|c|}
\hline \multirow[t]{2}{*}{ Learning resources } & \multicolumn{2}{|c|}{$\begin{array}{l}\text { Extensive ICT- } \\
\text { using science } \\
\text { teachers }\end{array}$} & \multicolumn{2}{|c|}{$\begin{array}{l}\text { Non-extensive } \\
\text { ICT-using science } \\
\text { teachers }\end{array}$} & \multirow[t]{2}{*}{ Effect size } \\
\hline & M & SD & M & SD & \\
\hline Equipment and hands-on materials & 3.08 & 0.79 & 2.91 & 0.82 & 0.21 \\
\hline Tutorial/exercise software & 2.29 & 0.84 & 1.83 & 0.73 & 0.58 \\
\hline General office suite & 2.71 & 0.86 & 2.08 & 0.81 & 0.75 \\
\hline Multimedia production tools & 2.07 & 0.87 & 1.56 & 0.73 & 0.64 \\
\hline Data-logging tools & 1.77 & 0.82 & 1.48 & 0.67 & 0.39 \\
\hline Simulations/modelling software/digital learning games & 1.84 & 0.80 & 1.47 & 0.62 & 0.52 \\
\hline Communication software & 2.02 & 0.94 & 1.56 & 0.78 & 0.53 \\
\hline Digital resources & 2.40 & 0.83 & 1.92 & 0.76 & 0.61 \\
\hline Mobile devices & 1.51 & 0.83 & 1.29 & 0.64 & 0.30 \\
\hline Smart board/interactive whiteboard & 1.29 & 0.66 & 1.14 & 0.45 & 0.27 \\
\hline Learning management system & 1.73 & 0.87 & 1.38 & 0.65 & 0.46 \\
\hline
\end{tabular}

$1=$ never $2=$ sometimes; $3=$ often $4=$ nearly always

equipment, for the most frequently used ICT applications medium effect sizes $(\geq 0.5$ but $<0.8$ ) between the two groups of science teachers were found, which was of course not unexpected. Both groups of science teachers make the least use of mobile devices, smart boards, and learning management systems. Also specific software for science education, such as data logging and simulation and modeling software is not used frequently. Yet, it must be noted that a medium effect size was found for simulation and modeling software, indicating that extensive ICT-using science teachers do use these ICT applications more frequently than their non-extensively ICT-using colleagues.

\subsubsection{Teaching practices}

Table 4 shows the difference between science teachers who use ICT extensively and those teachers who do not use ICT extensively with regard to the frequency with which they conduct a variety of teaching practices. The results show that except for classroom management, science teachers who use ICT extensively (that is once a week or more) use each of the teaching practices more often than science teachers who do not use ICT in such an extensive manner, but the differences between the two groups are not very large, as the effect sizes are small. Except for mediating communication between students and experts a medium effect size $(\geq 0.5$ but $<0.8)$ has been found. As was the case with the use of learning resources (also with regard to teaching practices) the rank order of the various teaching practices only slightly differed between extensive and non-extensive users. In both groups classroom management, whole class instruction, and assessing students' progress through tests is conducted most frequently, while liaising with others (in and outside the school) for student collaborative activities and organizing communication between students 
Table 4 Comparison of teaching practices of extensive and non extensive ICT-using science teachers (M, $\mathrm{SD}$, and effect size)

\begin{tabular}{|c|c|c|c|c|c|c|}
\hline \multirow[t]{2}{*}{ Teaching practices } & \multicolumn{2}{|c|}{$\begin{array}{l}\text { Extensive } \\
\text { ICT-using } \\
\text { science } \\
\text { teachers }\end{array}$} & \multicolumn{2}{|c|}{$\begin{array}{l}\text { Non- } \\
\text { extensive } \\
\text { ICT-using } \\
\text { science } \\
\text { teachers }\end{array}$} & \multicolumn{2}{|c|}{ Effect size ${ }^{*}$} \\
\hline & M & SD & M & SD & $\begin{array}{l}\text { Teaching } \\
\text { practice }\end{array}$ & $\begin{array}{l}\text { Use of ICT } \\
\text { in teaching practice }\end{array}$ \\
\hline Whole class instruction & 3.18 & 0.74 & 3.09 & 0.76 & 0.12 & 0.59 \\
\hline Provide remedial or enrichment instruction & 2.51 & 0.80 & 2.24 & 0.83 & 0.33 & 0.61 \\
\hline Advise in exploratory and inquiry activities & 2.85 & 0.75 & 2.53 & 0.77 & 0.42 & 0.45 \\
\hline Monitor student-led whole-class presentations & 2.57 & 0.84 & 2.20 & 0.81 & 0.45 & 0.57 \\
\hline Assess students' learning through tests & 2.92 & 0.76 & 2.86 & 0.81 & 0.08 & 0.43 \\
\hline $\begin{array}{l}\text { Provide feedback to individuals and/or small } \\
\text { groups of students }\end{array}$ & 2.86 & 0.76 & 2.63 & 0.82 & 0.29 & 0.50 \\
\hline $\begin{array}{l}\text { Use classroom management to ensure } \\
\text { an orderly, attentive classroom }\end{array}$ & 3.26 & 0.83 & 3.25 & 0.82 & 0.01 & 0.42 \\
\hline Monitor collaboration among students & 2.81 & 0.81 & 2.54 & 0.82 & 0.33 & 0.49 \\
\hline $\begin{array}{l}\text { Mediate communication between } \\
\text { students and experts }\end{array}$ & 1.98 & 0.86 & 1.58 & 0.72 & 0.50 & 0.44 \\
\hline $\begin{array}{l}\text { Liaise with others for student } \\
\text { collaborative activities }\end{array}$ & 2.05 & 0.82 & 1.68 & 0.73 & 0.48 & 0.43 \\
\hline Provide counselling to individual students & 2.78 & 0.83 & 2.63 & 0.86 & 0.18 & 0.51 \\
\hline $\begin{array}{l}\text { Collaborate with caretakers monitoring } \\
\text { students' learning }\end{array}$ & 2.62 & 0.91 & 2.32 & 0.91 & 0.33 & 0.39 \\
\hline
\end{tabular}

$1=$ never $2=$ sometimes; $3=$ often $4=$ nearly always; ${ }^{*}$ Effect size, showing the magnitude of the difference in teaching practices and ICT use between extensive and non-extensive ICT using science teachers

and experts, is done less frequently. It should be noted that the first three items mentioned belong to what Law and Chow (2008) called the traditionally important practice orientation while the last ones belong to the connectedness orientation (a specific sub-construct of the innovative practice orientation, see also Table 2). In addition to asking the science teachers about the frequency in which they use various teaching practices, they were also asked whether they use ICT in this teaching practice. Although extensive users use ICT more often in their science teaching practice, there is not a big difference in the rank order of activities in which science teachers use ICT. Both groups use ICT most for whole class instruction and tests (part of the traditionally important orientation), as well as for remediation, inquiry activities, and student presentations, which are part of the lifelong learning orientation. In Table 4 effect sizes showing the magnitude for differences in ICT use in teaching practices between extensive and non-extensive science teachers are presented. Medium effect sizes $(\geq 0.5$ but $<0.8)$ are found for whole class instruction, remediation, and student-led whole class presentations, providing feedback and counseling to students, which indicate a meaningful difference in ICT use between the two groups of teachers for these teaching practices. 


\subsubsection{Student practices}

Table 5 shows the difference between extensive ICT-using science teachers and nonextensive ICT-using science teachers on the frequency with which a variety of student practices occur in their classrooms. Generally the results show small effect sizes between extensive ICT-using and non-extensive ICT-using science, in favor of the first group, except for 'students working at the same pace', which happens a little more often in the classes of the non-extensive using science teachers. Medium effect sizes $(\geq 0.5$ but $<0.8)$ were only found to favor student practices of extensive ICTusing teachers, with respect to 'determination of own learning goals' and the 'students giving presentations'. These two learning practices are considered important in the innovative practice orientation and belong according to Law and Chow (2008) to the sub-construct lifelong learning paradigm (see Table 2). However, although a difference is found it should be noted that both practices do not happen frequently. The rank order of the activities differed only slightly between extensive and non-extensive users. In both groups completing worksheets, working at the same pace, and answering questions to tests or evaluations are the most

Table 5 Comparison of student practices of extensive and non extensive ICT-using science teachers (M, $\mathrm{SD}$, and effect size)

\begin{tabular}{|c|c|c|c|c|c|c|}
\hline \multirow[t]{2}{*}{ Student practices } & \multicolumn{2}{|c|}{$\begin{array}{l}\text { Extensive } \\
\text { ICT-using } \\
\text { science } \\
\text { teachers }\end{array}$} & \multicolumn{2}{|c|}{$\begin{array}{l}\text { Non- } \\
\text { extensive } \\
\text { ICT-using } \\
\text { science } \\
\text { teachers }\end{array}$} & \multicolumn{2}{|c|}{ Effect size ${ }^{*}$} \\
\hline & M & $\mathrm{SD}$ & M & SD & $\begin{array}{l}\text { Student } \\
\text { practice }\end{array}$ & $\begin{array}{l}\text { ICT use in } \\
\text { student } \\
\text { practice }\end{array}$ \\
\hline Students working at the same pace and/or sequence & 2.78 & 0.78 & 2.98 & 0.806 & -0.26 & 0.63 \\
\hline Students working at their own pace & 2.69 & 0.78 & 2.41 & 0.78 & 0.36 & 0.66 \\
\hline Complete worksheets, exercises & 2.92 & 0.75 & 2.92 & 0.76 & 0.00 & 0.52 \\
\hline Give presentations & 2.37 & 0.75 & 2.01 & 0.69 & 0.50 & 0.58 \\
\hline Determine own content goals for learning & 2.11 & 0.78 & 1.65 & 0.68 & 0.63 & 0.60 \\
\hline $\begin{array}{l}\text { Explain and discuss own ideas } \\
\text { with teacher and peers }\end{array}$ & 2.58 & 0.75 & 2.36 & 0.75 & 0.29 & 0.45 \\
\hline $\begin{array}{l}\text { Collaborate with peers from schools within } \\
\text { and/or outside the country }\end{array}$ & 1.41 & 0.67 & 1.18 & 0.45 & 0.40 & 0.37 \\
\hline Answer tests or respond to evaluations & 2.71 & 0.79 & 2.69 & 0.80 & 0.03 & 0.56 \\
\hline Self and/or peer evaluation & 2.31 & 0.86 & 1.97 & 0.79 & 0.41 & 0.53 \\
\hline $\begin{array}{l}\text { Reflect on own learning experience, } \\
\text { adjust own learning strategy }\end{array}$ & 2.00 & 0.88 & 1.68 & 0.76 & 0.39 & 0.44 \\
\hline Communicate with outside parties & 1.69 & 0.72 & 1.42 & 0.57 & 0.41 & 0.47 \\
\hline $\begin{array}{l}\text { Contribute to the local community } \\
\text { through learning activities }\end{array}$ & 1.78 & 0.79 & 1.48 & 0.63 & 0.42 & 0.46 \\
\hline
\end{tabular}

$1=$ never $2=$ sometimes; $3=$ often $4=$ nearly always; ${ }^{*}$ Effect size, showing the magnitude of the difference in teaching practices and ICT use between extensive and non-extensive ICT using science teachers 
frequently used student practices. According to Law and Chow (2008) these practices are part of the traditionally important pedagogical orientation. Contributing to the community, communicating with outside parties, and collaborating with peers from other schools is done less frequently in the two groups of science teachers. These practices are part of the sub-construct connectedness orientation (see Table 2).

Extensive ICT-using science teachers use ICT more often with their students, but there is not a large difference in the rank order of activities in which science teachers use ICT. ICT is used most by both groups for giving presentations (part of the lifelong learning orientation), followed by students learning at the same pace and students completing worksheets (both part of the traditionally important orientation). Effect sizes showing the magnitude of differences in ICT use in student practices between extensive and non-extensive science teachers are presented in Table 5. Medium effect sizes $(\geq 0.5$ but $<0.8)$ were found for students working at the same pace, completing worksheets, and answering questions to tests or evaluations (part of the traditionally important orientation), as well as for students learning at their own pace, students giving presentations, students determining their own goals, and for students understanding self and peer evaluation (part of the lifelong learning orientation).

\subsubsection{Perceived impact of ICT on student outcomes}

Table 6 presents the perceived impact of ICT on student outcomes as reported by the science teachers. In fact the same pattern as described above is also found for the perceived impact of ICT on student outcomes. Extensive ICT-using science teachers see a larger impact of ICT on student outcomes. Yet, the rank order of impact of ICT on student outcomes differs only slightly, with ICT skills, learning motivation,

Table 6 Perceived impact on student outcomes; comparison of extensive and non- extensive ICT-using science teachers (M, SD, and effect size)

\begin{tabular}{|c|c|c|c|c|c|}
\hline \multirow[t]{2}{*}{ Student outcomes } & \multicolumn{2}{|c|}{$\begin{array}{l}\text { Extensive ICT-using } \\
\text { science teachers }\end{array}$} & \multicolumn{2}{|c|}{$\begin{array}{l}\text { Non-extensive ICT-using } \\
\text { science teachers }\end{array}$} & \multirow[t]{2}{*}{ Effect size } \\
\hline & M & SD & M & SD & \\
\hline Subject matter knowledge & 4.05 & 0.67 & 3.73 & 0.62 & 0.49 \\
\hline Learning motivation & 4.26 & 0.67 & 3.92 & 0.64 & 0.52 \\
\hline Information-handling skills & 4.14 & 0.68 & 3.79 & 0.65 & 0.53 \\
\hline Problem-solving skills & 3.80 & 0.73 & 3.46 & 0.64 & 0.50 \\
\hline Self-directed learning skills & 3.98 & 0.74 & 3.63 & 0.67 & 0.50 \\
\hline Collaborative skills & 3.81 & 0.81 & 3.49 & 0.69 & 0.43 \\
\hline Communication skills & 3.88 & 0.83 & 3.51 & 0.72 & 0.48 \\
\hline ICT skills & 4.31 & 0.63 & 3.95 & 0.59 & 0.59 \\
\hline Ability to learn at their own pace & 3.89 & 0.74 & 3.58 & 0.63 & 0.45 \\
\hline Self esteem & 3.81 & 0.70 & 3.46 & 0.66 & 0.49 \\
\hline Achievement gap among students & 3.54 & 0.83 & 3.33 & 0.69 & 0.28 \\
\hline
\end{tabular}

$1=$ decreased a lot, $2=$ decreased, $3=$ no impact, $4=$ increased, $5=$ increased al lot 
information handling skills, and subject matter knowledge ranked highest. Medium effect sizes $(\geq 0.5$ but $<0.8)$ are found for ICT skills, learning motivation, information handling skills, problem solving skills, and self-directed learning skills.

After recoding ${ }^{2}$ we compared the answers - their perceived contribution - of the extensive ICT-using science teachers to student outcomes in their regular practice and for the satisfying practice they had nominated (see Fig. 3) in particular. The effect sizes were small. Hence, there doesn't appear to be a large difference in the contribution attributed to ICT to student outcomes in the regular pedagogical practices and the specified satisfying practice of these science teachers.

\section{Discussion}

In this study we aimed to get an understanding of characteristics of ICT-supported pedagogical practices in relation to changes in society. Pedagogical practices were considered part of the innovative practice orientation when they reflected demands for education in the information society, and were seen as part of the traditionally important practice orientation when they reflected teaching and learning that fits the industrial society (see also Table 1). We argued that education is searching for a new balance in what is pedagogically appropriate given the changes taking place in society. We first analyzed characteristics of pedagogical practices that extensive ICTusing science teachers considered to their most satisfying. This was followed by an analysis of the characteristics of the regular pedagogical practices of the extensive ICT-using science teachers along with the pedagogical practices of science teachers who did not use ICT extensively.

The results of this study show that in the satisfying practices, about which the extensive ICT-using science teachers reported, ICT contributed to an increase in a variety of student outcomes and teaching practices. According to a large majority of the science teachers, the use of ICT in the satisfying examples contributed to an increase in student outcomes that are considered important in the innovative practice orientation (information handling skills) as well as traditionally important orientation (subject matter knowledge and ICT skills). It is noteworthy that many science teachers-but not the large majority-observed an increase in skills such as collaborative skills, communication skills, self directed learning skills, and problem solving skills. These skills are considered highly relevant to the innovative practice orientation and consequently to the information society. In addition ICT contributed to self-esteem and an increase in motivation to learn. These outcomes are important to facilitate learning in the innovative and traditionally important practice orientations. In the satisfying pedagogical practices teachers reported increases related to both the innovative practice orientation (variation in learning activities, adaptation to individual students) and the traditionally important practice orientation (quality of instruction). Also, an increase of available content and learning resources, beneficial for both the innovative and traditionally important practice orientations, was noticed by a large majority of science teachers. It was expected that in the

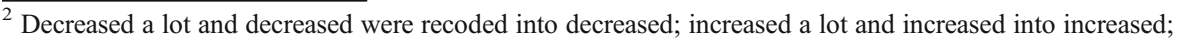
no impact stayed the same.
} 
satisfying practices about which the science teachers reported responsibilities for teaching and learning between teachers and students would also shift. However, the analysis showed that, in general, the teachers were still the main initiators of teaching and learning activities in the pedagogical practice they had in mind. The only activities in which students took the lead were organizing grouping and demonstrating achievement, but even here less than half of the science teachers reported this situation.

Extensive ICT-using science teachers who provided the satisfying pedagogical practices and used ICT on a weekly basis, made more use of ICT applications as a learning resource than their colleagues who did not use ICT so extensively. However, traditional learning resources (laboratory equipment, calculators) were used by most from both groups of teachers in their regular teaching practice, immediately followed by general ICT applications. Specific software for science, such as data logging and simulations were not used very often by both groups of teachers, a finding similar to what Becker et al. (1999) also found in 1999 in a large survey in the USA. Extensive ICT-using science teachers also attributed a larger impact to ICT in their student outcomes than the non-extensive ICT using science teachers. But except for these differences, only gradual differences were found in the pedagogical practices of extensive ICT-using and non-extensive ICT-using science teachers. The most remarkable difference is that extensive ICT-using science teachers overall score somewhat higher in the frequency in which they apply different teaching and student practices. The results of the study also show that the most frequently applied teaching and student practices of both extensive ICT-using science teachers and non-extensive ICT-using science teachers still reflect the traditionally important orientation to learning. In addition, the results of this study also suggest that ICT contributes to both traditionally and innovative practice orientations.

From the results of this study we may conclude that the traditional important orientation (within the context of ICT use) is still dominant in the pedagogical practices of grade 8 science teachers. This holds for extensive ICT-using science teachers as well as non-extensive ICT-using science teachers. Yet it is noteworthy that many science teachers observe in ICT-supported practices that they find most satisfying an increase in student outcomes and teaching practices due to ICT, which can be characterized as part of the innovative practice orientation and reflects the demands of the information society. This finding may indicate that nowadays a relevant number of science teachers - across educational systems - are trying to find ways to incorporate ICT, particularly general ICT applications, in their pedagogical practices to realize pedagogical practices that are considered relevant in the $21 \mathrm{st}$ century. These findings are consistent with findings from the two previous SITES studies (Voogt 1999; Kozma 2003). Reflecting on the findings of this study we argue that it is not so surprising that the traditionally important orientation to teaching and learning is still dominant across educational systems, but that it is promising that the innovative practice orientation seems to become more visible in educational practices across systems. The findings of this study, as well as the findings from the earlier SITES studies, give reason to believe that the equilibrium between traditionally important and innovative practice orientations is changing. Yet, it is unclear whether this change is a matter of shifting towards the innovative practice orientation or whether already a new balance is found and practiced in education. 
We must realize that it is difficult for schools and teachers to create experiences in order to better understand pedagogical practices that are appropriate for our society. Schools and teachers have to operate within the context of the state or national curriculum and examination requirements. Although these curriculum and examination requirements may vary in the extent to which they leave room for innovative practices, one may assume that in many situations teachers are limited in their possibilities for change. Policy makers, in their attempts to envision what is important for education in the 21st century, often send ambiguous messages to teachers and schools. On the one hand they require both teachers and schools to focus on basic skills and assume that pedagogies reflecting the traditionally important practice orientation will result in better performance. Yet on the other hand they challenge education to change and to prepare students for the competencies needed in the 21 st century and emphasize pedagogies - with a specific role for ICT in particular-that reflect the innovative practice orientation. Teachers and schools do not have an easy task in coping with these two often conflicting demands. Finding a balance between the traditionally important and innovative orientations to teaching and learning is a challenging task for all stakeholders involved in the enterprise called education.

Open Access This article is distributed under the terms of the Creative Commons Attribution Noncommercial License which permits any noncommercial use, distribution, and reproduction in any medium, provided the original author(s) and source are credited.

\section{References}

Anderson, R. (2008). Implications of the information and knowledge society for education. In J. Voogt \& G. Knezek (Eds.), International handbook of information technology in primary and secondary education. New York: Springer.

Becker, H. J., Rawitz, J. L., \& Wong, Y. T. (1999). Teacher and teacher-directed student use of computers and software. Irvine, CA: University of California.

Carstens, R., \& Pelgrum, W.J. (2009). Second information technology in education study. SITES 2006 technical report. Amsterdam: IEA.

Cohen, J. (1969). Statistical power analysis for the behavioral sciences. New York: Academic.

Bransford, J.D., Brown, A.L., \& Cocking, R.R. (Eds.).(2000). How people learn: Brain, mind, experience, and school (expanded ed.). Washington, DC: National Academy Press.

European Commission. (2002). eEurope 2005: An information society for all. Brussels, Belgium: European Commission.

Kozma, R. B. (ed). (2003). Technology, innovation and educational change: A global perspective. Eugene, OR: International Society for Technology in Education.

Law, N., \& Chow, A. (2008). In N. Law, W.J. Pelgrum \& T. Plomp (Eds.), Pedagogy and ICT use in schools around the world. Findings from the IEA SITES 2006 study (pp 121-179). CERC Studies in comparative education. Hong Kong: Comparative Education Research Centre, The University of Hong Kong, and Dordrecht: Springer.

Law, N., Pelgrum, W. J., \& Plomp, T. (2008). Pedagogy and ICT use in schools around the world. Findings from the IEA SITES 2006 study. CERC Studies in comparative education. Hong Kong: Comparative Education Research Centre, The University of Hong Kong, and Dordrecht: Springer.

Organisation for Economic Co-operation and Development (OECD). (2004). Lifelong learning. Observer, February, 1-8. Retrieved June 30, 2005, from http://www.oecd.org/dataoecd/17/11/29478789.pdf 
Pelgrum, W. J., \& Anderson, R. A. (eds). (1999). ICT and the emerging paradigm for lifelong learning: A worldwide educational assessment of infrastructure, goals and practices. Amsterdam: International Association for the Evaluation of Educational Achievement.

Voogt, J. (1999). Most satisfying experiences with ICT. In W. J. Pelgrum \& R. E. Anderson (Eds.), ICT and the emerging paradigm for life long learning: A worldwide educational assessment of infrastructure, goals and practices (pp. 199-216). Amsterdam: IEA.

Voogt, J. (2003). Consequences of ICT for aims, contents, processes and environments of learning. In J. van den Akker, W. Kuiper \& U. Hameyer (Eds.), Curriculum landscapes and trends (pp. 217-236). Dordrecht: Kluwer.

Voogt, J. (2008). Satisfying Pedagogical Practices Using ICT. In N. Law, W.J. Pelgrum \& T. Plomp. Pedagogy and ICT use in schools around the world. Findings from the IEA SITES 2006 study (pp 221-250). CERC Studies in comparative education. Hong Kong: Comparative Education Research Centre, The University of Hong Kong, and Dordrecht: Springer.

Voogt, J., \& Pelgrum, W. J. (2005). ICT and curriculum change. Human technology: an Interdisciplinary Journal on Humans in ICT Environments, 1(2), 157-175. 